\title{
Analysing the Impact of Anthropogenic Factors on the Environment in India
}

\author{
Bhagirath Behera (Corresponding author) \\ Department of Humanities and Social Sciences \\ Indian Institute of Technology Kharagpur \\ Kharagpur-721302, West Bengal, India
}

Tel: 91-3222-283-630 E-mail: bhagirath@hss.iitkgp.ernet.in

\author{
Rajeev Vishnu \\ Department of Humanities and Social Sciences \\ Indian Institute of Technology Kharagpur \\ Kharagpur-721302, West Bengal, India \\ E-mail: r.rajeevvishnu@gmail.com
}

\author{
Received: July 26, $2011 \quad$ Accepted: September 6, $2011 \quad$ Published: December 1, 2011 \\ doi:10.5539/enrr.v1n1p117 URL: http://dx.doi.org/10.5539/enrr.v1n1p117
}

\begin{abstract}
Using carbon dioxide as a surrogate measure of various environmental impacts, this paper analyses the effects of anthropogenic factors on $\mathrm{CO}_{2}$ emissions in India. The paper uses the STIRPAT model with data for 1960-2007. The results show that urbanisation has the largest potential negative effects on the environment, followed by population, service sector, industrial sector and GDP per capita. While analysing the potential effects of various anthropogenic factors on the environment, accounted for by average annual growth rates, population emerges as the single largest factor contributing towards emissions, followed by urbanisation (the degree of contribution to change in $\mathrm{CO}_{2}$ emissions by these factors are $33.8 \%$ and $29.7 \%$ respectively). Hence, there is a need for serious consideration of policy changes with regard to demographic and urban planning in India in order to reduce the effects of these factors on the environment. For instance, India could adopt a two-child policy like the one-child policy in China to control population growth. Unplanned and haphazard urbanisation can lead to inefficient use of energy resources that may hinder the efforts to reduce carbon dioxide emissions in India. Hence sustainable urban planning across Indian states is very much essential for better management of environmental resources.
\end{abstract}

Keywords: IPAT, STIRPAT, GDP, Population, Environment, Impact, Ridge regression, India

\section{Introduction}

Assessing the environmental impact due to various anthropogenic factors has been the topic of active research for quite some time (Dietz \& Rosa, 1994; Madu, 2008; Lin et al., 2009). It has now become quite apparent that anthropogenic activities are modifying the global environment on an unprecedented scale and have already altered the chemical composition of the atmosphere (e.g. the emission of greenhouse gasses and ozone depleting substances), dramatically changed the land cover over vast areas of the globe, altered major biogeochemical cycles and accelerated the extinction of species (York et al., 2003b). In recent years much of the discussion has been on the issue of climate change which is believed to have been caused by global warming due to emissions of carbon dioxide and other greenhouse gases (GHGs) in the atmosphere. There is widespread consensus among the scientific community that these GHGs are the consequence of human activities (IPCC, 2007; Stern, 2006).

With increasing levels of GHGs in the atmosphere and its cumulative effects on economy as well as the global ecosystem, there is an urgent need to better understand the influence of various anthropogenic factors on the environment, to help find appropriate policy solutions. One important question that arises in this context is which anthropogenic factors are driving this environmental change. There exists a large body of research that has attempted to understand the relative importance of various anthropogenic factors that drive environmental 
change. According to some studies economic growth and population size are the primary determinants of a wide variety of environmental impacts (York et al., 2001; Rosa \& York, 2002; Dietz et al., 2007). Along with population and economic growth other factors such as technology, political and economic institutions, attitudes and beliefs are also found to be relevant factors that affect the ecosystem at large (Stern et al., 1992; Dietz \&Rosa, 2004).

There is consensus in existing empirical studies that the relationship between population, economic growth and environmental quality is complex, that they are intricately interconnected, and that thorough research is necessary for a deeper understanding of this relationship. In this context, a first attempt was made by Ehrlic and Holdren (1972) to formulate a fundamental identity that shows how environmental impact is the result of the number of people living in an area and their affluence and implemented technology. The identity is popularly known as IPAT:

$$
\text { Impact }=\text { Population } \times \text { Affluence } \times \text { Technology }
$$

A detailed discussion on the origin and evolution of this identity is presented in the next section.

The objective of the present study is to identify the important anthropogenic factors, and assess the magnitude of their impacts on the environment in India, the most populous and second fastest growing economy in the world, using the modified version of IPAT identity. Ever since India embarked on the path of economic reform in 1991, it has recorded phenomenal economic growth with massive expansion of industrial and service sectors, and registered record inflows of FDI and an increased share of domestic investment, sprawling urbanisation and increased consumption levels as a result of rising per capita income. All these economic activities have put tremendous pressure on the country's environmental resources, putting the future growth of the economy in danger. India is the third largest emitter of GHGs in the world, after China and USA, in absolute terms (UN, 2007), and considering the rapid economic growth the country has achieved in recent years it can be expected that this is likely to increase at an exponential scale if not checked. Though the per capita emissions of the country remains at a very low level (in fact one of the least in the world), India cannot afford to evade the responsibility of reducing GHG emissions and hence arresting damage to ecosystems. According to the Millennium Assessment, damages to ecosystems affects the welfare of human beings (MA, 2005). More specifically, India's people are often more vulnerable to its effects because a large proportion of the population (more than 60 percent) is directly dependent on primary economic activities such as agriculture, forestry, and fisheries for their survival and well-being.

Little progress has been made in regard to the identification of various anthropogenic factors and their magnitudes that drive GHG emissions and other environmental change in India. Empirical studies from countries across the world show the varying effects of anthropogenic factors on environmental change. They range from the dominant effects of population and urbanisation in China (Lin et al., 2010), to economic growth and population in Nigeria (Madu, 2008). Interestingly, Madu (2008) found that urbanisation reduces the effects of impacts on the environment implying that modernisation brings about a reduction in environmental impacts. With increasing urbanisation and per capita income and hence per capita consumption, it would be interesting to assess the relative importance of various factors on the environmental impacts in India. Moreover, it appears that a large knowledge gap exists as far as the testing of the IPAT model in the Indian context is concerned. At least to our knowledge not a single study exists on India in this respect and hence there is a need to bridge this gap.

The paper is structured as follows. Section 2 presents a brief historical background of IPAT model and its gradual developments. Section 3 explains the data and variables used in the model, and discuss estimation techniques. Empirical results and discussion are presented in section 4. Section 5 provides some concluding remarks with policy implications.

\section{Methods}

As indicated above Ehrlich and Holdren $(1971,1972)$ were the first to use the IPAT model to describe the impact on the environment of a growing population. A detailed discussion on the importance of the model and its variants is presented in Chertow (2001). The equation basically explains how growing population, affluence of citizens and technological progress affects the environment. Impact on Environment is expressed as the multiplicative product of Population, Affluence and Technology. Hence the identity takes the form,

$$
I=P * A * T
$$

where I denotes the environmental impacts, $\mathrm{P}$ represents the population size, A represents affluence and $\mathrm{T}$ stands for the levels of technology.

Ever since this identity was developed researchers have used the model with modifications for a variety of reasons. For a comprehensive discussion on the developments of this model see Lin et al. (2009). Dietz and Rosa 
(1994) suggested a reformulation of the IPAT model considering the monotonous and rigid nature of the identity. They suggested an alternative stochastic version which allows the use of modern statistical tools used in the Social Sciences. The stochastic equation is known as STIRPAT: Stochastic Impact of Regression on Population, Affluence and Technology. York, Rosa and Dietz (2003b) introduced an additive regression model in which all variables are in logarithmic form, which facilitates estimation and hypothesis testing. Their paper points out that in the typical application of the basic STIRPAT model, $\mathrm{T}$ is included in the error term, rather than estimated separately, making it consistent with the IPAT model, where T is solved to balance I, P and A.

$$
\ln \left(I_{t}\right)=a+\alpha \ln \left(P_{t}\right)+\beta \ln \left(A_{t}\right)+e
$$

This makes the variables as well as the parameters easier to interpret. The following interpretations can be made based on the coefficients obtained in the model. Impacts that yield a coefficient equal to 1.0 are referred to as unit elastic, which indicates a proportional relationship between the driving force and the impact; a percentage change in the driving force produces an identical percentage change in impact. Coefficients $>1.0$ suggest an elastic relationship, indicating that an impact increases more rapidly than the driving force. Coefficients $<1.0$ (but $>0$ ) are indicative of an inelastic relationship, where impact is less responsive to changes in the driving force. Coefficients may also be negative. Values equal to -1.0 indicate negative unit elasticity, meaning that impact decreases proportionately in response to an increase in the driving force. Values $<-1.0$ indicate negative elasticity, meaning that impact decreases in greater proportion to an increase in the driving force. Values $<0.0$ but $>-1.0$ indicate negative inelasticity, meaning that impact decreases in lesser proportion to an increase in the driving force.

In another paper York et al. (2003a) explain the basic variables suggested in splitting the variables further. A presentation by Rosa and Dietz (2010) suggests the use of 11 other independent variables in addition to the basic ones they have suggested before. They also suggest that the error term should not merely include the Technology variable but also various other factors like social, political and cultural. This may amount to the " $B$ ", the behavioural variables suggested by Schultz (2002).

\section{Data and Variable Description}

The data used in this paper were obtained from the data bank of the World Bank (http://databank.worldbank.org). The data is available for the period 1960 to 2007.

As mentioned above the paper has used the following modified version of the STIRPAT model, which is based on the basic IPAT identity.

$$
\ln \left(C_{2}\right)=A+b \ln (P)+c \ln (U r P)+d \ln (\operatorname{InP})+e \ln (G D P p C)+f \ln (\operatorname{Ser})+g \ln (\operatorname{Ind})+\mathrm{U}
$$

Where $I$ is environmental impact using carbon dioxide emission as a proxy (appropriate justification is provided below), $P$ is population, $U r P$ is percentage of urban population, $\operatorname{In} P$ is the percentage of population between the age group of 15-60, GDPpC is per capita income, Ser and Ind are the percentage of GDP from the service and industrial sector respectively, $\mathrm{A}$ is a constant term, $\mathrm{U}$ is an error term, and b, c, d, e, f, g are the parameters of the independent variables to be estimated. All the variables were converted to the natural logarithms for ease of estimation.

Literature suggests that carbon dioxide emissions are highly correlated to ecological footprints (Cole \& Neumayer, 2004). In the absence of reliable data on ecological footprints, annual emissions data of carbon dioxide is used here. This proxy has been widely used by researchers as an overall impact on environment (Madu, 2008; Lin et al., 2009). In addition to the population variable in STIRPAT, two more variables viz. percentage of urban population and percentage of working class has been added in the model. The justification for the inclusion of these variables is to control the effects by urbanisation and working class population in particular on the environment. One of the primary reasons for rapid environmental degradation in India is due to increasing urbanisation which is caused by the increasing migration of workers from rural areas to urban centres. Similar trends of rural-urban migration have been observed in China and elsewhere (Lin et al., 2009). GDP per Capita is used as a proxy for affluence. Percentage share of GDP from service and industrial sectors are used to explain the effects of technology as well as affluence aspects of STIRPAT. More importantly, the inclusion of share of service sector as a variable in the model is justified on the ground that the service sector contributes more to GDP than the manufacturing sector and it is generally assumed that service sectors pollutes less than other sectors of the economy. Hence, it would be interesting to examine the effects of service sector on the environment. We assume that the other aspects of technology as well as cultural and behavioural aspects will be captured by the error term. The trends of these variables are presented below. 
Figure 1 shows carbon dioxide emissions in India for the period 1960 to 2005 . The figure clearly suggests that there has been a steady increase in carbon dioxide emissions in India over the period. It is also true that carbon dioxide emission is largely contributed by consumption of energy in addition to land use changes and other economic activities. India's energy requirements are met primarily by coal and other fossil fuels which are carbon intensive and are considered as dirty energy. There has been an average annual increase of $5.55 \%$ (over 1960-2007), with a total increase of $1237 \%$ over the period. Over all, it can be said that the environmental impacts of India has sharply increased especially since the 1980s and shows no sign of declining.

India's population has been growing at an annual growth rate of $2 \%$ (Table 1), which is quite high compared to other growing developing countries such as China (only 1\%). This is likely to have adverse impacts on the environment, as population growth is likely to increase energy consumption and increase the demand for industrial and agricultural products that can put more pressure on the environment. Urban population in India has increased at an average annual rate of $1.03 \%$ (Table 1). Urban annual average growth rate is $1.03 \%$ which is reasonably high.

Figure 4 indicates the trend in GDP per capita over the years. The GDP of India has grown significantly over the years, especially after 1991. With an Annual Average growth rate of $2.82 \%$, the GDP per capita has recorded an overall increase of almost $280 \%$ from 1960 to 2005 . Figure 5 and 6 indicates the pattern of trend in percentage of manufacturing and service sectors as percentage of GDP. Industry share has an average annual growth rate $0.83 \%$ and service sector share has an average annual growth rate of $0.71 \%$. Overall growth of the service and industrial sectors are $48 \%$ and $100 \%$ respectively.

Table 1 presents the summary of average annual growth rates of all the variables used in the model. Among all the variables, the growth rates of carbon dioxide emissions is found to be the highest $(5.5 \%)$, followed by the growth rate of GDP per capita.

\section{Results and Discussion}

The equation (4) was estimated for assessing the impacts of anthropogenic factors on the environment in India using the Ordinary Least Squares Regression estimation technique. The correlation test of the independent variables was done and is presented in Table 2. The test results indicate that all the independent variables are having the problem of high multicollinearity as can be observed in the correlation matrix in Table 2 . The Ordinary Least Square regression estimate of the STIRPAT model (presented in Table 3) gives Variance Inflation Factor (VIF) values for population, percentage of urban population, population between the age group 16-60, and GDP per capita. Percentage of GDP from service and industry sectors are higher than the minimum required number of 10 (see Table 4), which indicates a strong multicollinearity between these variables. With the problem of high multicollinearity the OLS estimation of the STIRPAT model may not be a good prediction of real relationship between the dependent and explanatory variables. Hence, eliminating the problem of multicollinearity is very much necessary to obtain better parameter estimates. One way to address the multicollinearity problem is to delete some of the highly correlated variables from the model, which would essentially result in information loss and thereby may affect the reliability of the estimates. However, as suggested by many researchers, one way to overcome the problem of multicollinearity without deleting any variables is by using ridge regression (Heorl, 1962; Lin et al, 2009).

In addition, Björkström (2001) provides the following advantages of Ridge regression over other methods to remove multicollinearity: (1) It does not require deletion of variables, (2) Better predictability even within the framework of Regression models, (3) In ridge regression, several principles are known for selecting the best parameter value, and to the extent the consequences of these principles have been explored, it has been within the framework of the standard regression mode.

This method requires a careful selection of an appropriate ridge regression coefficient $\mathrm{K}$. As it is a biased estimation, $\mathrm{K}$ should be chosen as small as possible and should simultaneously have small VIFs and steady going regression coefficients. In this case, $\mathrm{K}$ was calculated with a step length of 0.001 changing within $[0,1]$. This was done with the help of SPSS 15.0. The table shows the improvement in various parameters with K. While selecting $\mathrm{K}$, it is also necessary to ensure that the VIF values are reduced to the appreciable range $(<10)$. Stabilization of various parameters with $\mathrm{K}$ value is also necessary. The $\mathrm{K}$ value is chosen such that all these conditions are satisfied. The value of $\mathrm{K}$ chosen in this paper is 0.040 . The graphs and table below depict the selection procedure.

After the careful selection of K, parameters are estimated using SPSS 15.0. The regression results are presented in Table 6. 
Figure 9 shows the variation of $\mathrm{R}$ square with $\mathrm{K}$, which justifies the selection of $\mathrm{K}$, as $\mathrm{R}$ square shows very less decrement with the increment in $\mathrm{K}$.

With regards to the results of ridge regression, overall the model is highly significant with a $\mathrm{R}$ square value of $99 \%$. In regard to individual variables, except for one variable (population between the age group 16-60) all the variables have turned out to be significant with theoretically consistent positive signs of the coefficients which suggests that all the variables have impacted the environment to varying degrees (for degree see Table 7). For instance, population size has an impact coefficient of 0.88 . On the other hand, the variable urban population which is a proxy for urbanization contributes a major part of it with an elasticity coefficient of 1.29. Similarly, GDP per capita, a proxy for affluence, has a relatively smaller regression coefficient of 0.38 . Interestingly, the service sector has an impact coefficient of 0.70 which is higher than that of the Industry sector which has a coefficient of 0.417 . The higher coefficient of service sector seems slightly contradictory as one expects this sector to be less polluting and clean compared to the industrial sector, but given the size of the sector and its contribution to India's total GDP, one can expect such results to be realistic.

However, it would be interesting to compare the ecological elasticities obtained in this model for India with the ones which are found in other studies and countries. The ecological elasticity of population in India is 0.88 which is more or less close to 1 as suggested by the I-PAT identity. This is also similar to the global values of 0.972 and 0.922 obtained by York et al. (2003) and Cole and Neumayer (2003) respectively. This suggests that the pressure exerted by population in India is more or less similar to that of the world average. However, for China the value is 1.5 which is relatively very high (Lin et al., 2009). The percentage of urban population in India has an ecological elasticity of 1.5 which is quite high with regard to the global value of 0.663 (Neumayer, 2003). Since the urban population is expressed as the percentage of population living in urban areas in India, we have estimated the percentage change in carbon emissions caused by one percent change in percentage of urban population. This is equivalent to 0.01 percentage $(0.01 * 1 \%)$ of Urban population. For example if the urban population of a country is $25 \%$, a one percent increase of $25 \%$ (i.e. 0.25 , change to $25.25 \%$ ), we expect an increase in carbon emissions by $1.5 \%$. The variable working class in India has no significant elasticity coefficient which is again in line with the global trend suggested by Cole and Neumayer (2003).

GDP per capita has an elasticity coefficient which is relatively small (0.36). IPAT suggest this to be as one. This is in contrast to the value found by York et al. (2003) and Neumayer (2003) as 0.91 and 0.86 respectively. This small value might be because of the erratic nature shown by Indian GDP per capita over the years and relatively larger average carbon emissions - GDP ratio. However, our value is comparable to the values obtained by Lin et al. (2009) for China which is 0.23 . As mentioned before percentage share of services and manufacturing sector is indicative partly for the technological advancements which have elasticity coefficients of 0.71 and 0.40 respectively.

Though ecological elasticites gives us an idea about the effect of each factor on carbon emissions, the real contribution of each of these determinants can be calculated only if we analyze them taking into consideration the average annual growth rate of these factors. This is done by using the following simple formula.

\section{Degree of Contribution to change in Environmental Impact by each factor}

$$
\begin{gathered}
=\frac{\text { Ecological Elasticity of the factor }}{\text { Ratio of average annual growth rates of Carbon dioxide emissions to that factor }} \\
\text { For example : Degree of Contibution by Population }=\frac{\frac{\Delta C \mathrm{O}_{2}}{\frac{\mathrm{Cpop}}{p o p}} * \frac{(\mathrm{Avg} \cdot \text { grow of } \mathrm{Pop})}{\left(\mathrm{Avg} \cdot \text { grow of } \mathrm{CO}_{2}\right)}}{}
\end{gathered}
$$

It is shown in Table 7 that the main driving forces of environmental impact in India are population, urbanization and GDP per Capita, with degree of contribution about 32\%, 29\% and 19\% respectively. In combination, they have resulted in an overall environmental impact increase of $4.47 \%$.

\section{Conclusions}

The paper uses a multiple regression model to study the various anthropogenic determinants of carbon dioxide emissions in India. The results found are largely in confirmation with those suggested in the literature, with some variations which can be accounted for by reasons specific to India. The following conclusions can be drawn from the results obtained.

First, we found that population is one of the important factors that affect the environment, which is expected given the size and growth of India's population over the last few decades. Moreover, these results, as mentioned earlier, 
are found across studies in different countries. But this has tremendous significance in the context of India. With an average annual fertility rate of 2.68 percent the population of India is likely to increase in the coming years. Even if this rate is reduced significantly the Indian population is likely to increase because of the momentum it has achieved over the years. This may have an adverse impact on the environment as the demand for resources is also likely to increase very rapidly, as India has already 1.2 billion (according to census 2011 data) and an average density of population of 363.5 persons per square $\mathrm{km}$. The pressure exerted by population in India on the environment is important not just for India but also for the entire world. This call for serious thinking into India's demographic planning. A two-child policy similar to that of China's one-child policy could be implemented for controlling population growth. However in a democratic country like India it is likely to generate a huge debate among various constituents, and such draconian measures may not be adopted. Of course, access to education and improved health services, provision of social security measures, and increased awareness will go a long way in stabilizing population problems.

Second, urbanization in India has the highest ecological elasticity among all the determinant factors considered in the model, meaning that urbanization is adversely impacting the environment. As mentioned above, for three decades or so India's economic activities have been concentrated in cities which has become an important attraction for people in rural areas wishing to improve their livelihoods. Rural-urban migration enhances rapid urbanization as the demand for houses, transportation and other infrastructure increases. However, it should be noted that unplanned and haphazard urbanisation can lead to inefficient use of energy resources that may hinder the efforts to reduce carbon dioxide emissions in India. Hence sustainable urban planning across Indian states is very much essential for better management of environmental resources. In addition, development of infrastructure in rural areas and generation of employment and livelihoods opportunities may help reduce migration and pressure on environment.

Third, GDP per capita, which is used as a proxy for affluence, has also significant contribution to environmental impact. It is found that carbon dioxide emissions increase with affluence. Though the elasticity coefficient for GDP per capita is relatively low, considering the fast pace of growth in GDP the degree of contribution to environmental impact is found to be high. Fourth, service and manufacturing sectors have significant contribution to environmental degradation in India. This also suggests that technological changes in India have not been very environment friendly and there is tremendous scope for improvement in technology in these sectors. More importantly, to achieve sustainable use and management of environmental resources there is a need for a radical change in human behaviour with regard to ecologically sensitive factors. These changes must take place across different economic agents such as consumers, producers and policy makers.

In terms of the limitation and scope of the present study it is necessary to point out that this study has used carbon dioxide emission as an indicator for overall environmental impact by considering data at an aggregate level. To get more insights and in depth understanding the study can be extended to states and even regional levels which can enable us to come up with more specific policy suggestions. Also, the study can be extended by incorporating environmental impacts like land degradation, deforestation etc. Though this may be a deviation from the conservative IPAT model, the method could prove to be effective and worth attempting.

\section{Acknowledgements}

The authors would like to thank Prof. N. C. Nayak and Dr. Pulak Mishra for their valuable comments on the paper.

\section{References}

Björkström, A. (2001). Ridge regression and inverse problems. Stockholm: Stockholm University. Retrieved from: http://www2.math.su.se/matstat/reports/seriea/2000/rep5/report (26 August, 2008)

Chertow, M. R. (2001). The IPAT Equation and Its Variants. Journal of Industrial Ecology, 4(4), 13-29.

Cole, M., \& Neumayer, E. (2003). Examining the Impact of demographic Factors On Air Pollution. Labor and Demography 0312005, EconWPA.

Commoner, B. (1972). Making peace with the planet.New York: New Press.

Dietz, T., \& Rosa E.A. (1994). Rethinking the Environmental Impacts of Population, Affluence and Technology. Human Ecology Review 1, 277-300.

Dietz, T., Rosa, E. A., \& York, R. (2007). Driving the human ecological footprint. Frontiers in Ecology and the Environment, 5(1), 13-18. http://dx.doi.org/10.1890/1540-9295(2007)5[13:DTHEF]2.0.CO;2 
Dietz, T., York, R., \& Rosa, E.A. (2001). Ecological democracy and sustainable development Paper Presented at the 2001 Open Meeting of the Human Dimensions of Global Environmental Change Research Community, Rio de Janeiro, Brazil.

Ehrlich, P., \& Holdren, J. (1972). One-dimensional economy .Bulletin of Atomic Science, 28(5), 16-27.

Ehrlich, P., \& Holdren, J. (1971). Impact of population growth. Science, 171, 1212-7.

Hoerl, A. (1962). Application of ridge analysis to regression problems. Chemical Engineering Program, 58, $54-9$

IPCC. (2007). Climate Change. The IPCC Fourth Assessment Report, Intergovernmental Panel on climate change, Cambridge University Press, New York.

Lin, S., Zhao, D., \& Marinova, D. (2009). Analysis of the environmental impact of China based on STIRPAT model. Environmental Impact assessment Review, 29, 341-347. http://dx.doi.org/10.1016/j.eiar.2009.01.009

Madu, I.A. (2008a). The environmental impacts of regional disparity in population and wealth distribution in Nigeria. Environment, Development and Sustainability, 11, 265-276. http://dx.doi.org/10.1007/s10668-007-9109-0

Madu, I.A. (2008b). The impacts of anthropogenic factors on the environment in Nigeria. Journal of Environmental Management. 90(3), 1422-1426. http://dx.doi.org/10.1016/j.jenvman.2008.08.009

Schulze PC. (2002). I = PBAT. Ecological Economics, 40(2), 149-50. http://dx.doi.org/10.1016/S0921-8009(01)00249-X

Shi, A. (2003). The impact of pollution pressure on global carbon dioxide emissions, 1975-1996: evidence from pooled cross-country data. Ecological Economics. 44, 29-42. http://dx.doi.org/10.1016/S0921-8009(02)00223-9

Stern, P.C., Young, O.R., \& Druckman, D. (1992). Global Environmental Change: Understanding the Human Dimensions. Washington, DC: National Academy Press.

Stern, N. (2006). The Economics of Climate Change: The Stern Review. Cambridge University Press, London.

United Nations Statistics Division. (2007). Millennium Development Goals indicators: Carbon dioxide emissions (CO2), thousand metric tonnes of $\mathrm{CO} 2$ (collected by CDIAC).

York R., Rosa E.A., \& Dietz T. (2003a). Footprints on the Earth: The Environmental Consequences of Modernity. American Sociological Review, 68(2), 279-300. http://dx.doi.org/10.2307/1519769

York, R., Rosa, E.A., \& Dietz T. (2003b). STIRPAT, IPAT and ImPACT: Analytic Tools for Unpacking the Driving Forces of Environmental Impacts. Ecological Economics, 46, 351-365. http://dx.doi.org/10.1016/S0921-8009(03)00188-5

York, R., Rosa, E., \& Dietz, T. (2001). The population and affluence elasticity of environmental impacts. Paper Presented at the Pacific Sociological Association Annual Meeting in San Francisco.

Table 1. Growth rates of variables from 1960-2005

\begin{tabular}{|c|c|}
\hline Variables & Average Annual growth rate \\
\hline Carbon dioxide emissions & 5.55 \\
\hline Population & 2 \\
\hline Urban Population percentage & 1.03 \\
\hline Population between the age group 15-60 & 0.24 \\
\hline GDP Per capita & 2.82 \\
\hline Services \% of GDP & 0.71 \\
\hline Industry \% of GDP & 0.83 \\
\hline
\end{tabular}


Table 2. Correlation matrix for independent variables

\begin{tabular}{|c|c|c|c|c|c|c|}
\hline Variable & Population & $\begin{array}{c}\text { Urban } \\
\text { Population } \\
\text { percentage }\end{array}$ & $\begin{array}{c}\text { Population } \\
\text { b/w the age } \\
\text { group 15-60 }\end{array}$ & $\begin{array}{c}\text { GDP } \\
\text { Per } \\
\text { capita }\end{array}$ & $\begin{array}{c}\text { Services } \\
\% \text { of } \\
\text { GDP }\end{array}$ & $\begin{array}{c}\text { Industry } \\
\% \text { of } \\
\text { GDP }\end{array}$ \\
\hline Population & 1 & & & & & \\
\hline $\begin{array}{c}\text { Urban Population } \\
\text { percentage }\end{array}$ & 0.998 & 1 & & & & \\
\hline $\begin{array}{c}\text { Population between } \\
\text { the age group 15-60 }\end{array}$ & 0.946 & 0.937 & 1 & & \\
\hline GDP Per capita & 0.942 & 0.927 & 0.988 & 1 & & \\
\hline Services \% of GDP & 0.936 & 0.928 & 0.977 & 0.969 & 1 & \\
\hline Industry \% of GDP & 0.922 & 0.939 & 0.837 & 0.812 & 0.84 & 1 \\
\hline
\end{tabular}

Table 3. OLS regression results for the impacts of anthropogenic factors on the environment

\begin{tabular}{|c|c|c|c|c|c|}
\hline \multicolumn{6}{|c|}{ OLS Regression Results } \\
\hline \multicolumn{2}{|l|}{ Variables in the Equation } & \multicolumn{2}{|c|}{ Coefficients } & \multirow[b]{2}{*}{$\mathrm{T}$} & \multirow[b]{2}{*}{ Significance } \\
\hline & & B & Std.Error & & \\
\hline Population & $\mathrm{b}$ & 0.121 & 0.822 & 0.15 & 0.884 \\
\hline Urban Population percentage & $\mathrm{c}$ & 4.07 & 1.592 & 2.56 & $0.014 *$ \\
\hline Population between the age group $15-60$ & $\mathrm{~d}$ & -6.199 & 1.38 & -4.49 & $0.001 *$ \\
\hline GDP Per capita & $\mathrm{e}$ & 0.815 & 0.157 & 5.17 & $0.001 *$ \\
\hline Services $\%$ of GDP & $\mathrm{f}$ & 0.945 & 0.245 & 3.78 & $0.001 *$ \\
\hline Industry $\%$ of GDP & $\mathrm{g}$ & -0.32 & 0.236 & -1.37 & 0.178 \\
\hline Constant & & 15.754 & 14.51 & 1.09 & 0.284 \\
\hline R square & & 0.9973 & Adjusted R Square & 0.996 & \\
\hline F statistic & & 2549.52 & & & \\
\hline Probability(F statistic) & & $0.001 *$ & & & \\
\hline & & & *Signifi & at $1 \%$ & vel \\
\hline
\end{tabular}

Table 4. Variance Inflation Factors (VIFs) of the explanatory variables

\begin{tabular}{|c|c|c|}
\hline Variable & VIF & $1 /$ VIF \\
\hline Population & 1431.4 & 0.000699 \\
\hline Urban Population percentage & 1369.9 & 0.00073 \\
\hline Population between the age group 15-60 & 84.08 & 0.011893 \\
\hline GDP Per capita & 67.35 & 0.014849 \\
\hline Services \% of GDP & 23.57 & 0.042425 \\
\hline Industry \% of GDP & 20.29 & 0.049275 \\
\hline Mean VIF & 499.42 & \\
\hline
\end{tabular}


Table 5. The Variation in parameters with increment in K (Obtained using SPSS 5.0)

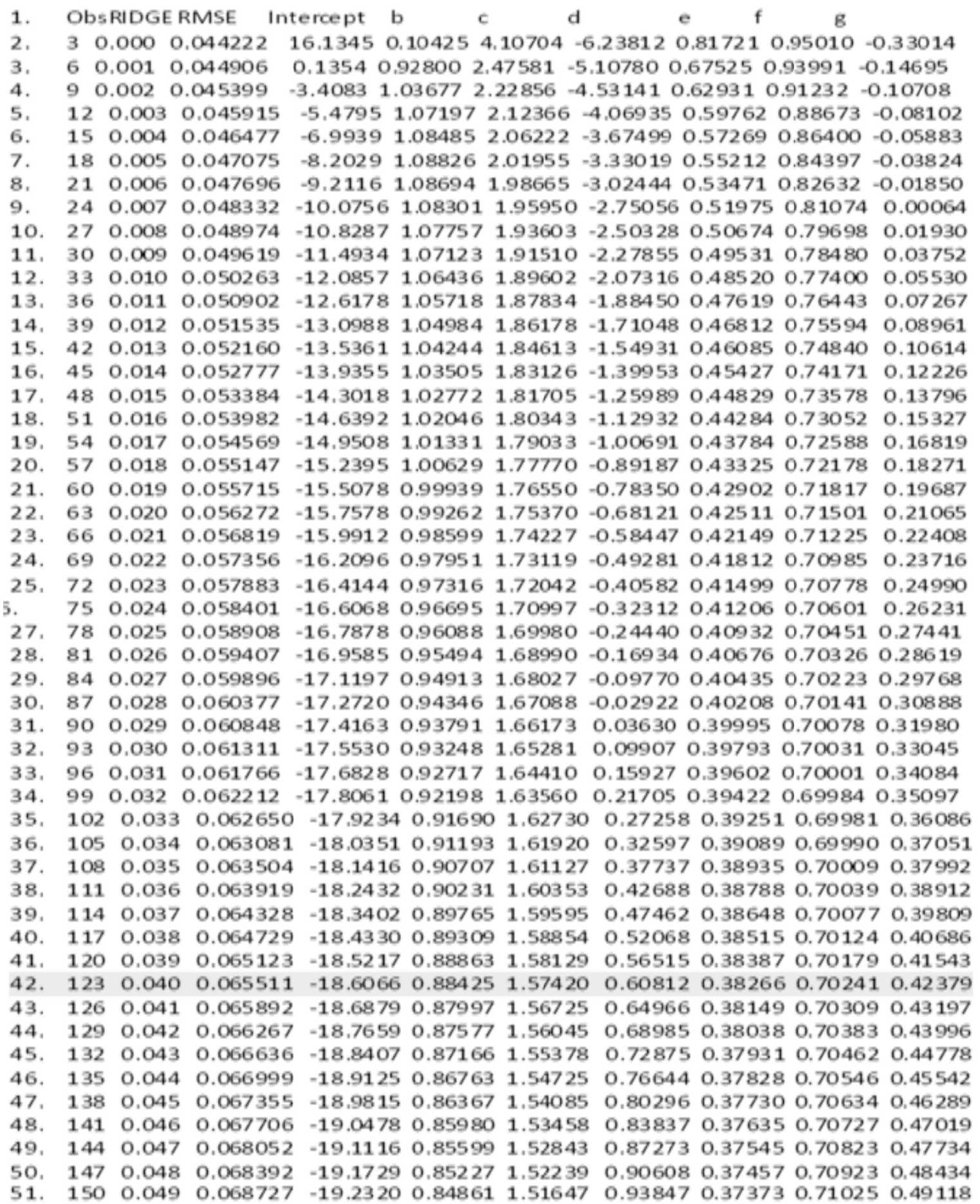


Table 6. Ridge Regression results $(\mathrm{K}=0.04)$

\begin{tabular}{|c|c|c|c|c|c|}
\hline Variables in the Equation & \multicolumn{3}{|c|}{ Coefficients } & & \\
\hline & \multicolumn{2}{|r|}{$\mathrm{B}$} & Std.Error & $\mathrm{T}$ & Significance \\
\hline Population & $\mathrm{b}$ & 0.885296 & 0.0483802 & 18.298721 & $0.001 *$ \\
\hline Urban Population percentage & $\mathrm{c}$ & 1.5778293 & 0.0855428 & 18.444904 & $0.001 *$ \\
\hline Population between the age group 15-60 & $\mathrm{d}$ & 0.5971682 & 0.4725567 & 1.2636962 & 0.429 \\
\hline GDP Per capita & $\mathrm{e}$ & 0.3818786 & 0.048381 & 7.8931537 & $0.001 *$ \\
\hline Services \% of GDP & $\mathrm{f}$ & 0.7050081 & 0.1652116 & 4.2673036 & $0.001 *$ \\
\hline Industry \% of GDP & $\mathrm{g}$ & 0.417588 & 0.1443539 & 2.8928076 & $0.006^{*}$ \\
\hline Constant & & -18.5806 & 1.4096702 & -13.18081 & $0.001 *$ \\
\hline R square & & 0.9945 & $\begin{array}{l}\text { Adjusted } \\
\text { R Square }\end{array}$ & 0.8544 & \\
\hline$F$ statistic & & 1159.5902 & & & \\
\hline Probability(F statistic) & & $0.001 *$ & & & \\
\hline & & & *Significan & at $1 \%$ leve & f Significan \\
\hline
\end{tabular}

Ridge Regression with $k=.04$

Table 7. Degree of contribution of anthropogenic factors towards change of environmental impacts

\begin{tabular}{|c|c|c|c|c|}
\hline & $\begin{array}{c}\text { Average } \\
\text { Annual growth } \\
\left.\text { rate( } \mathrm{b}_{\mathrm{i}}\right)\end{array}$ & $\begin{array}{c}\text { Regression } \\
\text { coefficient } \\
\left(\mathrm{r}_{\mathrm{i}}\right)\end{array}$ & $\begin{array}{c}\text { Effect of change } \\
\text { of Environmental } \\
\text { Impact }\left(\mathrm{e}_{\mathrm{i}}=\mathrm{r}_{\mathrm{i}}{ }^{*} \mathrm{~b}_{\mathrm{i}}\right)\end{array}$ & $\begin{array}{c}\text { Degree of Contribution to } \\
\text { change of Environmental } \\
\left.\text { Impact (= } \mathrm{e}_{\mathrm{i}} / \mathrm{a}\right)\end{array}$ \\
\hline $\begin{array}{c}\text { Carbon dioxide } \\
\text { emissions(a) }\end{array}$ & 5.55 & 0.89 & 1.77 & 31.89 \\
\hline $\begin{array}{c}\text { Population } \\
\text { Urban Population } \\
\text { percentage }\end{array}$ & 1.03 & 1.58 & 1.62 & 29.25 \\
\hline GDP Per capita & 2.82 & 0.38 & 1.08 & 19.4 \\
\hline $\begin{array}{c}\text { Services \% of } \\
\text { GDP }\end{array}$ & 0.71 & 0.71 & 0.5 & 9.07 \\
\hline $\begin{array}{c}\text { Industry \% of } \\
\text { GDP }\end{array}$ & 0.83 & 0.42 & 0.35 & 6.25 \\
\hline Constant & & -18.58 & 0.23 & 4.13 \\
\hline
\end{tabular}

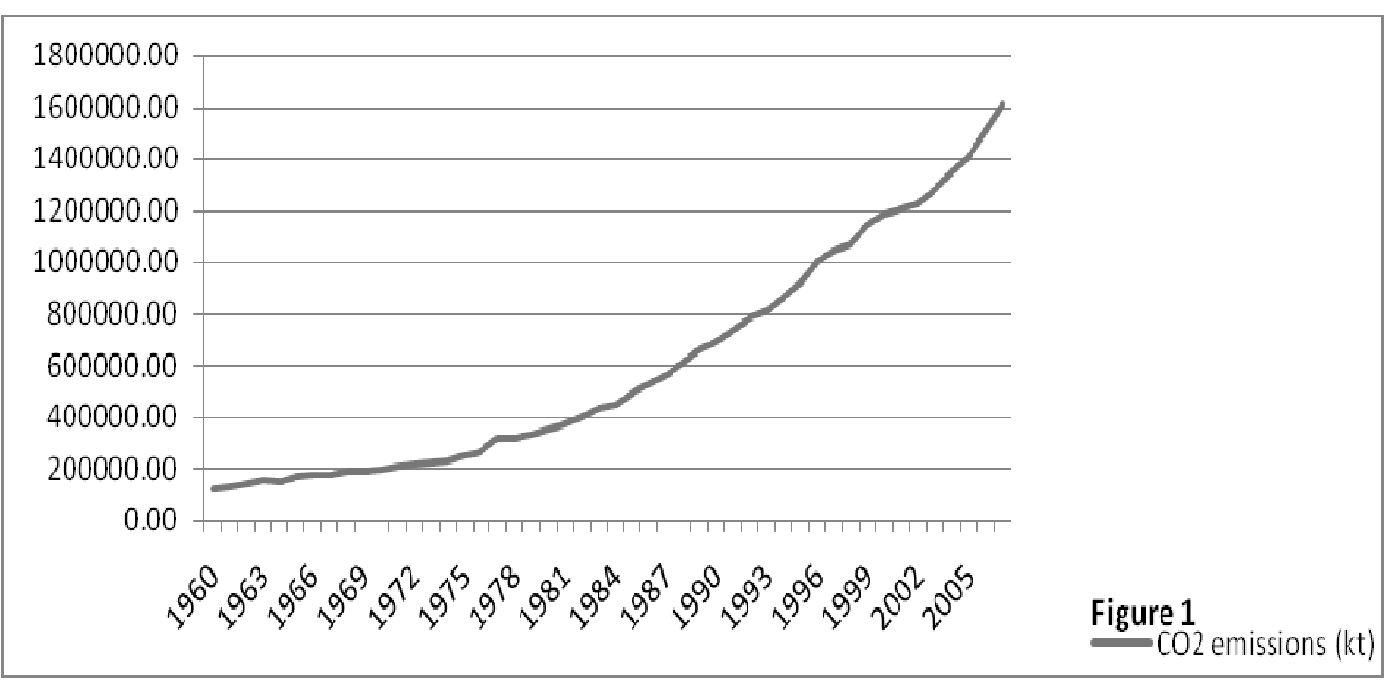

Figure 1. Carbon Emission in India (1960-2005) 


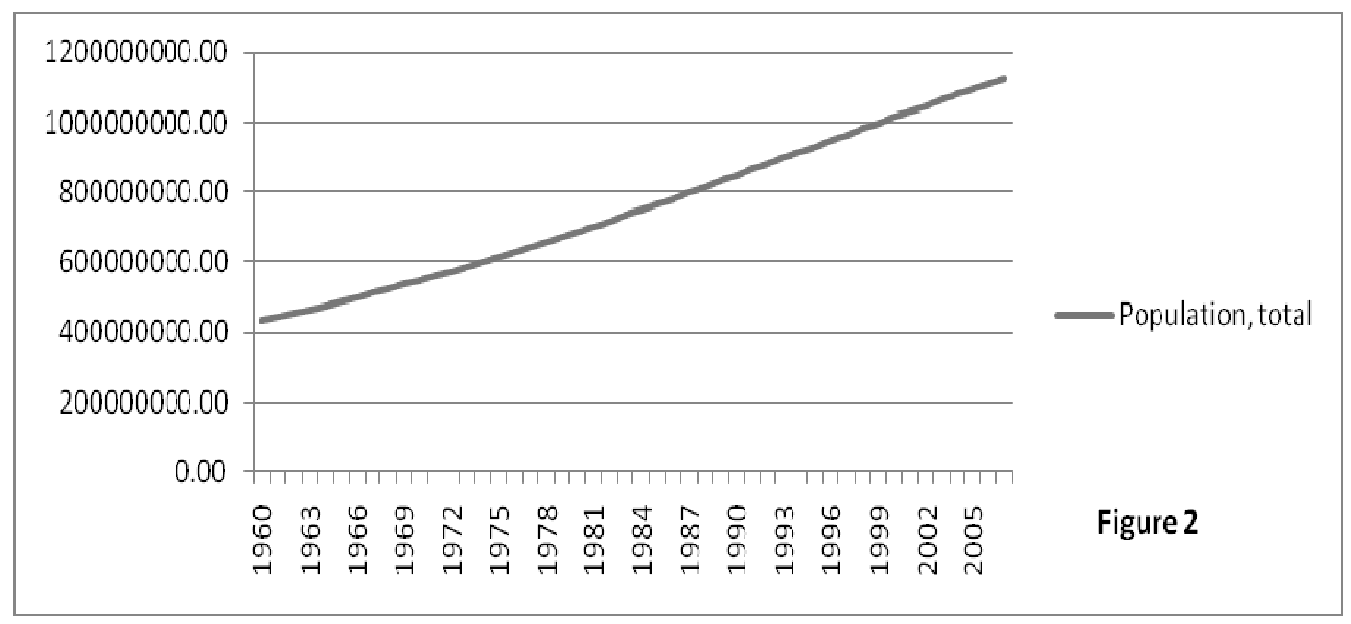

Figure 2. Population trend in India

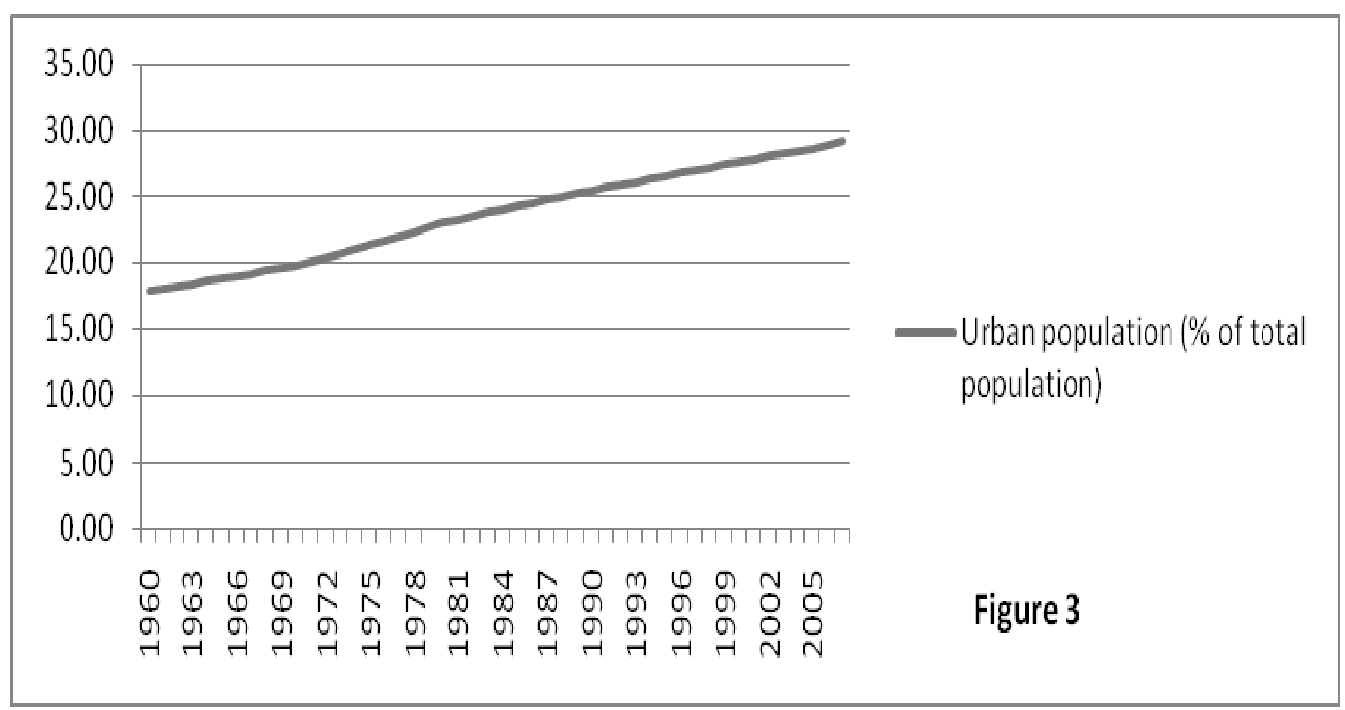

Figure 3. India's urban population (1960-2005)

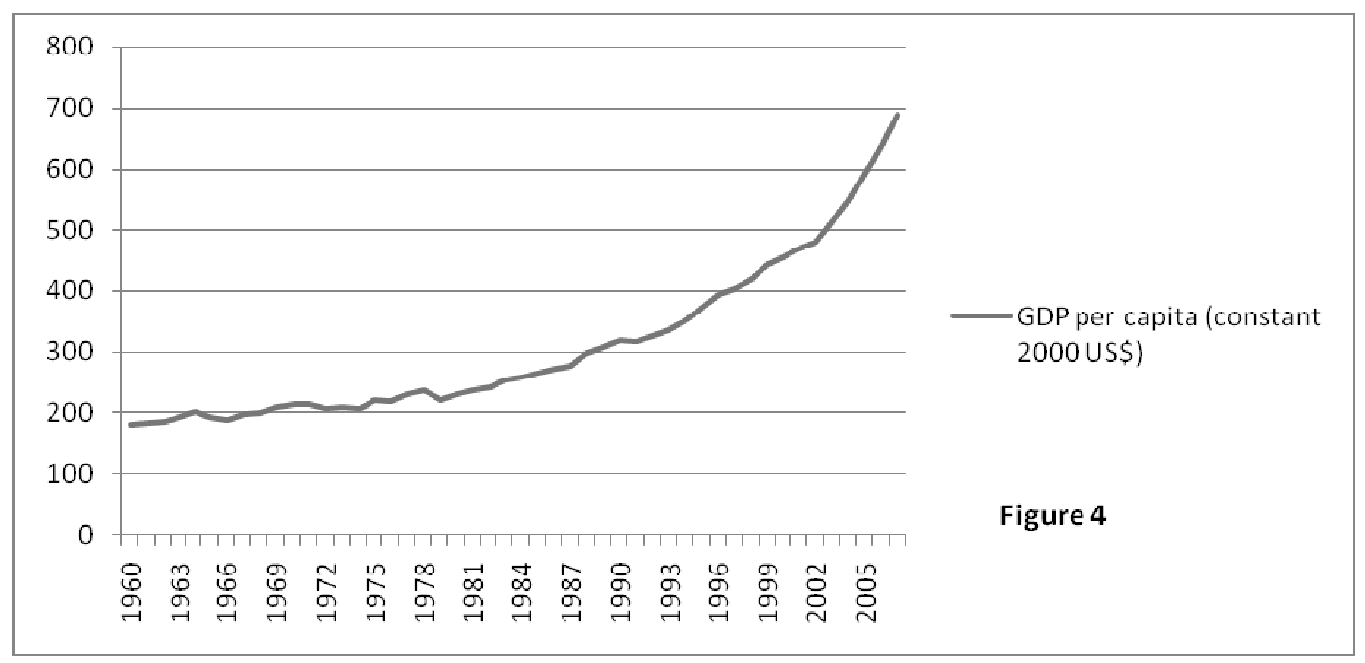

Figure 4. GDP per capita in US Dollars 


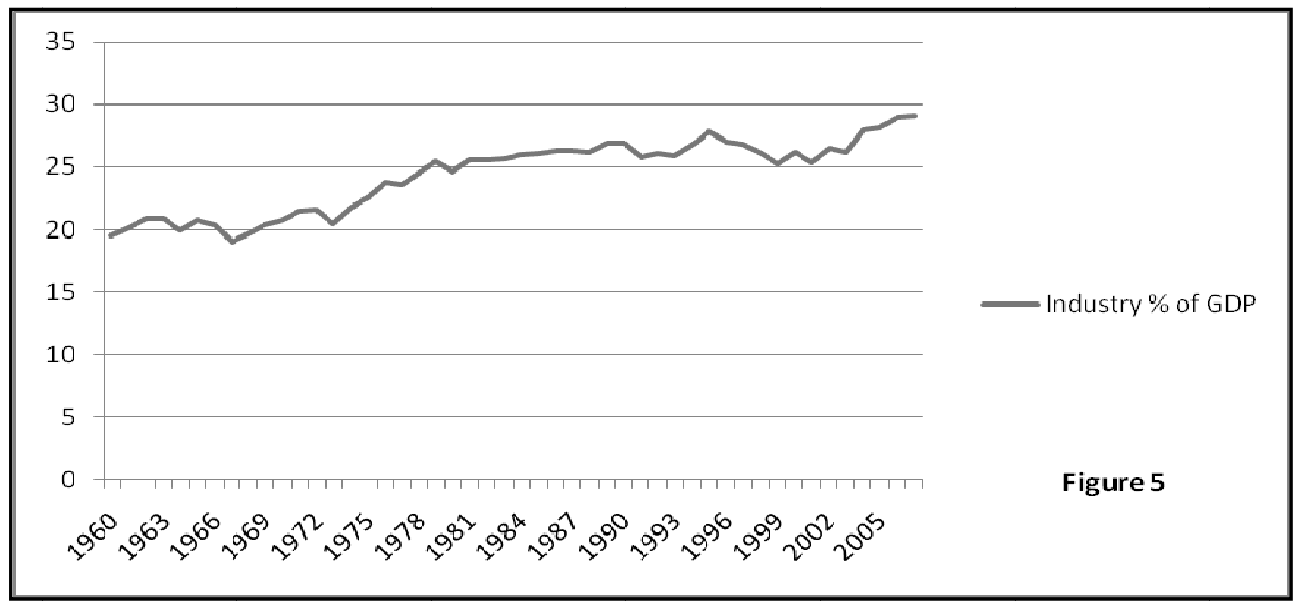

Figure 5. Share of GDP from Industry to total GDP

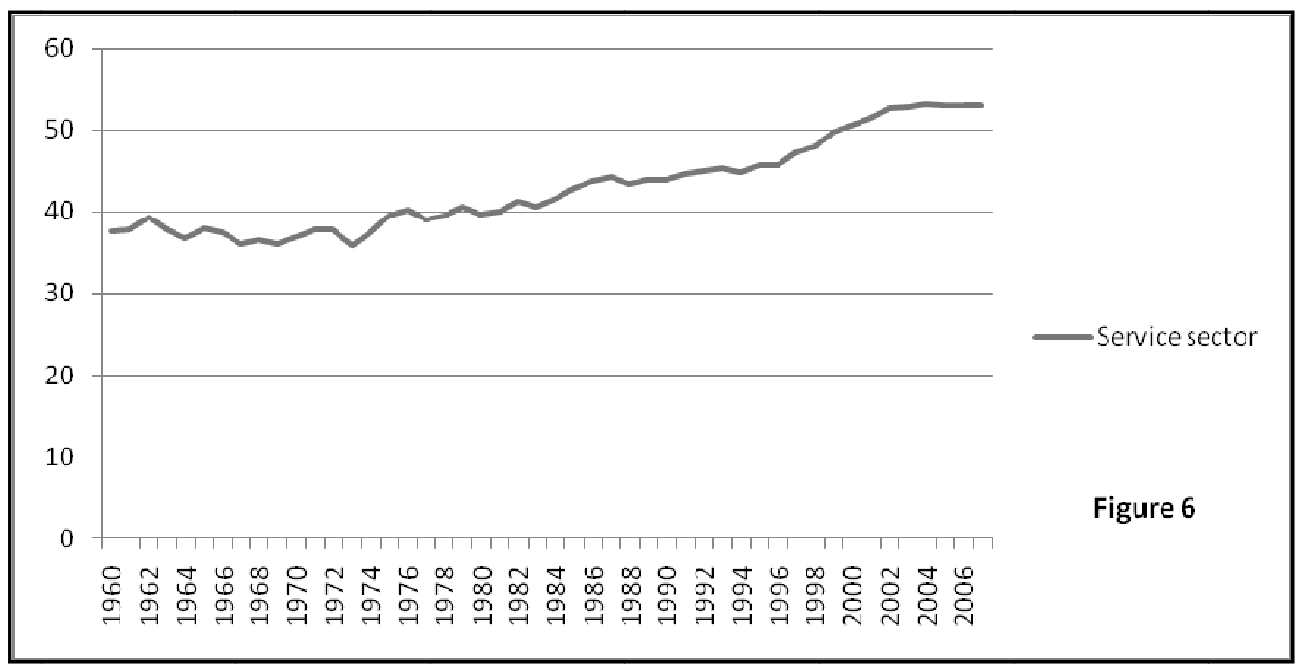

Figure 6. Share of GDP from service sector to total GDP

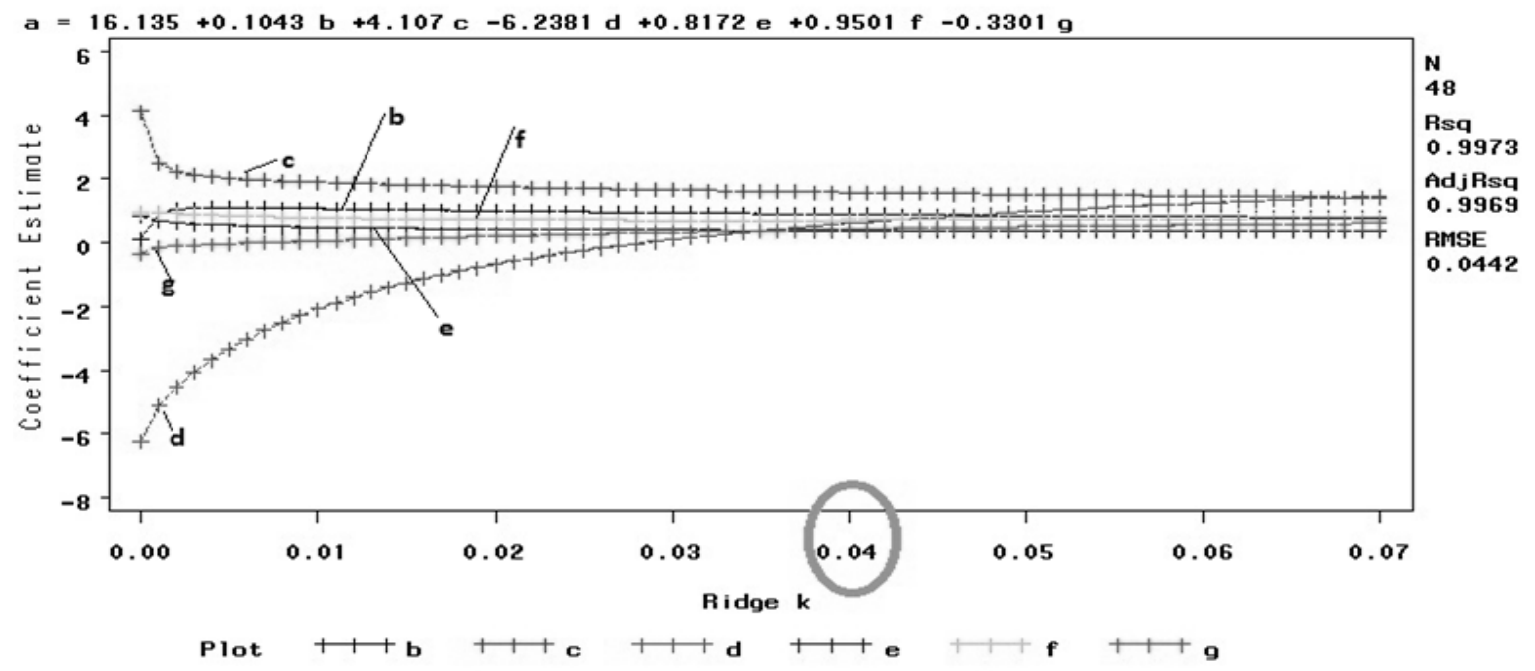

Figure 7. The graph shows how the parameters get stabilized with increment in K( Using SAS 3.0) 
Variance Inflation Factors

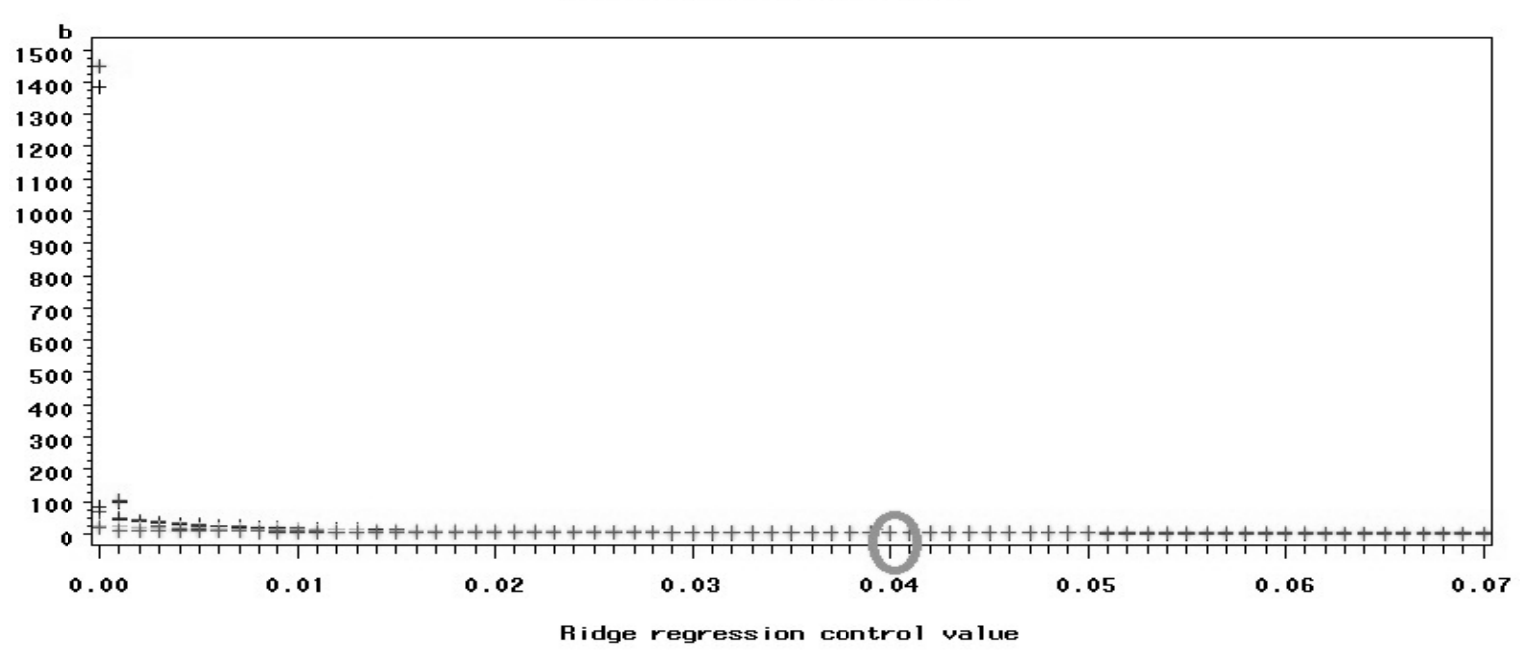

Figure 8. The graph shows the decline in VIFs with increment in K(obtained using SAS 3.0)

R-SQUARE VS. K

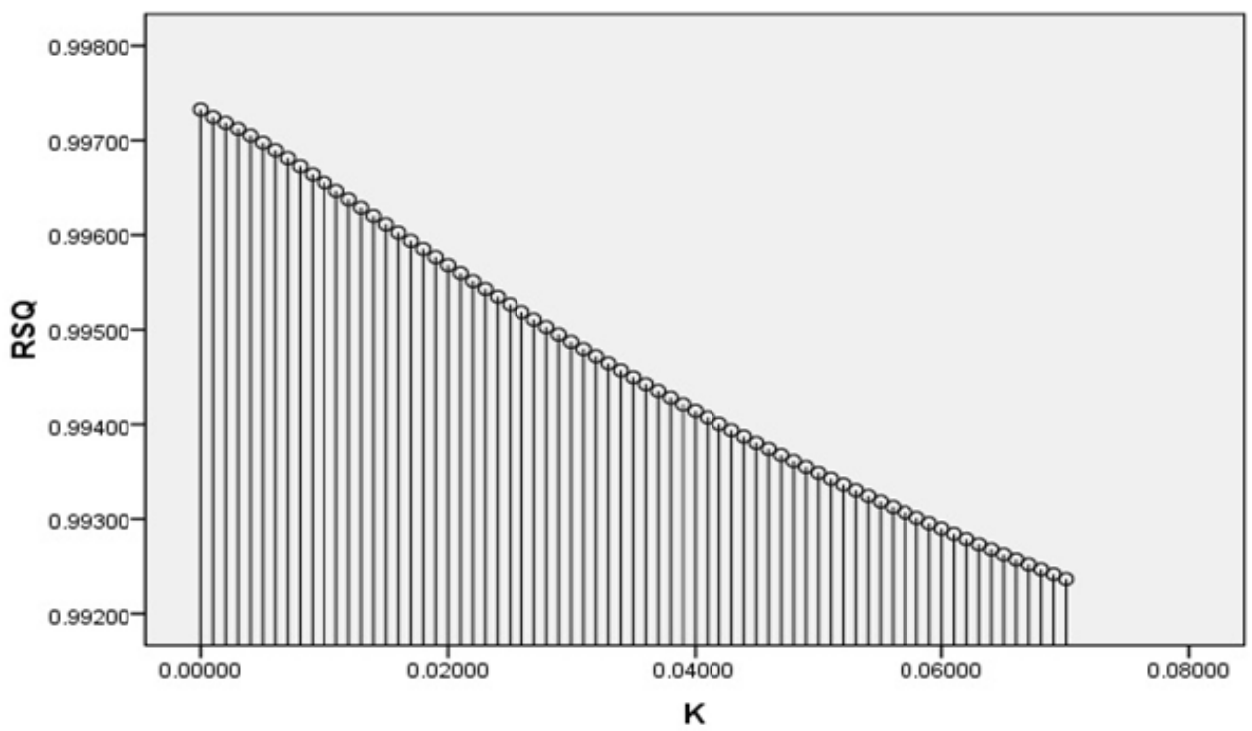

Figure 9. Graph showing variation of $\mathrm{R}$ square with $\mathrm{K}$ 